\title{
Differences in coronary artery disease complexity and associations with mortality and hospital admissions among First Nations and non-First Nations patients undergoing angiography: a comparative retrospective matched cohort study
}

\author{
Annette Schultz PhD RN, Lindsey Dahl MSc, Elizabeth McGibbon PhD RN, Jarvis Brownlie PhD, \\ Catherine Cook MD MSc, Basem Elbarouni MD, Alan Katz MBChB MSc, Thang Nguyen MD, \\ Jo-Ann V. Sawatzky PhD RN, Heather J. Prior MSc, Moneca Sinclaire PhD, Karen Throndson MN RN, \\ Randy Fransoo PhD
}

\section{Abstract}

Background: First Nations people are more likely than the general population to experience long-term adverse health outcomes after coronary angiography. Our aim was to quantify the extent of coronary artery disease among First Nations and non-First Nations patients undergoing angiography to investigate differences in coronary artery disease and related health disparities.

Methods: We conducted a retrospective matched cohort study to compare health outcomes of First Nations and non-First Nations adult patients (> $18 \mathrm{yr}$ ) who underwent index angiography between Apr. 1, 2008, and Mar. 31, 2012, in Manitoba, Canada. The SYNTAX Score was used to measure and compare severity of coronary artery disease between groups. Primary outcomes of all-cause and cardiovascular mortality were compared between groups using Cox proportional hazard models adjusted by SYNTAX Score results and weighted by the inverse probability of being First Nations. Secondary outcomes included all-cause and cardiovascularrelated hospital admissions.

Results: The cohort consisted of 277 matched pairs of First Nations and non-First Nations patients undergoing angiography; the average age of patients was 56.0 (standard deviation 11.7) years. The median SYNTAX Score results and patient distributions across categories in the matched paired cohort groups were not significantly different. Although proportionally First Nations patients showed worse health outcomes, mortality risks were similar in the weighted sample, even after controlling for revascularization and SYNTAX Score results. Secondary outcomes showed that adjusted risks for hospital admission for acute myocardial infarction (adjusted hazard ratio [HR] 3.03, 95\% confidence interval [CI] 1.40-6.55) and for congestive heart failure (adjusted HR 3.84, 95\% Cl 1.37-10.78) were significantly higher among First Nations patients in the weighted sample.

Interpretation: The extent of coronary artery disease among matched cohort groups of First Nations and non-First Nations patients appears similar, and controlling for baseline sociodemographic characteristics, coronary artery disease risk factors and SYNTAX Score results explained higher mortality risk and most hospital admissions among First Nations patients. Although there is a need to decrease risk factors for coronary artery disease among First Nations populations, addressing individuals' behaviour without considering root causes underlying risk factors for coronary artery disease will fail to decrease health outcome disparities among First Nations patients undergoing angiography.

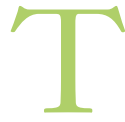

he shifting landscape of Canadian cardiovascular health over the last couple of decades presents 2 notable trends. First, the incidence of coronary artery disease and related mortality among the general population continue to decrease, ${ }^{1}$ which is attributed to improvements in lifestyle factors, diagnostic procedures and treatments. ${ }^{2-5}$ Second, before the 1980 s, rates of coronary
Competing interests: None declared.

This article has been peer reviewed.

Correspondence to: Annette Schultz, annette.schultz@ umanitoba.ca CMAJ Open 2020. DOI:10.9778/cmajo.20190171 
artery disease were lower among First Nations people in Canada than among the general population; ${ }^{6}$ however, rates of acute myocardial infarction (MI) and related mortality are increasing among First Nations people and are now reportedly higher for First Nations people than for the general population..$^{7-10}$ Additionally, First Nations people are less likely to undergo coronary angiography after an acute MI. ${ }^{11}$

This study is part of a larger project known as Debwewin (Annishinaabe) - truth of our hearts. Our team has explored disparities in coronary artery disease among First Nations and non-First Nations people through a series of secondary analysis studies of population administrative health data from Manitoba, Canada. ${ }^{12-14}$ Published findings from our studies to date have shown that First Nations people had lower rates of index angiography than non-First Nations people over a 9-year study period. ${ }^{12}$ Furthermore, among patients undergoing index angiography, First Nations patients had worse long-term health outcomes, received fewer outpatient physician visits and received fewer specialty services than non-First Nations patients, even after controlling for sociodemographic factors, comorbidities, cardiovascular medication use, revascularization treatments and history of a recent acute MI. ${ }^{13,14}$

In this fourth Debwewin study article, findings from our final exploration of disparities in coronary artery disease health are presented. Our aim was to investigate differences in coronary artery disease risk factors, comorbid conditions and underlying complexity of coronary artery disease among matched cohorts of First Nations and non-First Nations patients undergoing index angiography, and how these factors contribute to our understanding of differences in health outcomes among First Nations and non-First Nations patients undergoing index angiography in Manitoba.

\section{Methods}

\section{The Debwewin project}

The Debwewin project grew out of ideas shared during 2 key meetings. A meeting in 2012 with an Elders group at the First Nations Health and Social Secretariat of Manitoba (FNHSSM) led to securing a Canadian Institutes of Health Research (CIHR) planning grant to host a second meeting in 2013 with 36 people working in the field of Indigenous health, cardiac health care or health research; 31 were Indigenous people, of which 2 were Elders.

During the 5-year CIHR-funded Debwewin project, relations with FNHSSM were sustained through the approval of all study presentations and manuscripts by their research review board, and the production of annual newsletters for provincial Indigenous health technicians associated with FNHSSM. These newsletters were written for a lay audience with the aim to share study progress and outcomes. We also meet several times a year with a study Knowledge Keeper, Mary Wilson, Grandmother of the Four Paths, to discuss and seek guidance related to the study.

\section{Study design and setting}

In this study, we retrospectively compared a matched cohort of First Nations and non-First Nations adult patients (> $18 \mathrm{yr}$ ) who underwent index angiography in Manitoba between March 2008 and April 2012, using administrative data, chart audits and angiography images. Angiography procedures were identified in the health administrative data housed at the Manitoba Centre for Health Policy (MCHP) and were considered index events if the patient had not undergone an angiography or revascularization procedure (percutaneous coronary intervention $[\mathrm{PCI}]$ or coronary artery bypass graft $[\mathrm{CABG}]$ ) in the preceding 365 days. ${ }^{13}$ Index angiograms were chosen as representative of new episodes of cardiovascular care.

Previous research has determined that demographic characteristics of First Nations patients undergoing index angiography in Manitoba are distinct from those of non-First Nations patients: First Nations patients are younger, have a higher proportion of female patients and are more likely to be living in rural or remote areas. ${ }^{12}$ Given these differences, we matched non-First Nations patients to a random sample of First Nations patients based on age \pm 5 years, sex and area of residence, in addition to the index date \pm 1 year, and retrieved medical charts for those patients to collect additional baseline clinical information.

A sample size calculation indicated that 226 matched pairs were needed to ensure a 2 -tailed $\alpha$ of 0.05 with $80 \%$ power, which assumed similar differences in SYNTAX Score between First Nations and non-First Nations groups found through a pilot study (unpublished data, 2013).

\section{Study population}

In 2016, Manitoba's population was about 1.3 million people, of whom 155965 (12\%) were status First Nations people registered under the Indian Act..$^{15}$ There are 63 First Nations communities in Manitoba, and primary health care services for these residents are funded predominantly through federal programs. However, the provincial government funds all hospital, physician and specialist services in Manitoba, regardless of residence location or First Nations status. ${ }^{16}$ Therefore, all angiography procedures in Manitoba are captured in the provincial administrative health data system, and during the study period, all cardiac catheterizations were conducted at St. Boniface hospital in Winnipeg.

\section{Data sources and variables}

Three data sources were used in this study for identifying matching variables, baseline characteristics and extent of coronary artery disease. Each is addressed below in order of accessing the data source.

The Manitoba Centre for Health Policy houses the Manitoba Population Research Data Repository, which contains the administrative records for all health care services provided through the provincial health care system, as well as data sets from a variety of other sectors (see Table 1 for a list of data sets used in this study). Drawing on the population of Manitoba, 
Table 1: Health administrative data sets from the Manitoba Centre for Health Policy repository

\begin{tabular}{|ll|}
\hline Data set & \multicolumn{1}{c|}{ Description of study relevant data } \\
\hline Manitoba Health Insurance Registry & $\begin{array}{l}\text { The registry contains demographic information for most residents of Manitoba, including data for } \\
\text { all-cause mortality. }\end{array}$ \\
\hline Hospital abstracts & $\begin{array}{l}\text { These abstracts contain data on all hospital admissions in Manitoba, which were used to identify } \\
\text { patients who had received angiography, PCl and CABG, and hospital readmissions after } \\
\text { angiography. Appendix 1 (available at www.cmajopen.ca/content/8/4/E685/suppl/DC1) includes a } \\
\text { complete list of ICD and Canadian Classification of Health Interventions codes used in this study. }\end{array}$ \\
\hline Medical claims and medical services & $\begin{array}{l}\text { Claims for physician visits in offices, hospitals and outpatient departments were used to identify } \\
\text { baseline comorbidities. Twenty-five codes were taken from hospital abstracts and medical claims } \\
\text { data over a 1-year period immediately before the index angiography date. These data were used to } \\
\text { calculate the Charlson Comorbidity Index score, which reflects the level of comorbidity based on } \\
17 \text { comorbidity categories, each consisting of specific ICD-9 and ICD-10 diagnostic codes. }\end{array}$ \\
\hline 2006 and 2011 Canadian Census & $\begin{array}{l}\text { Estimation of income quintile scores were calculated using patient postal codes and their } \\
\text { associated Census dissemination area-level average household income. Separate income quintiles } \\
\text { were used for urban (Winnipeg and Brandon) and rural (all other areas) residents. }\end{array}$ \\
\hline Vital Statistics Mortality Registry & $\begin{array}{l}\text { This registry was used to identify mortality, specifically related to cardiovascular causes. } \\
\text { The Indian Registry System }\end{array}$ \\
$\begin{array}{l}\text { This system is maintained by the Department of Indigenous Services Canada and, with permission, } \\
\text { was linked to the Manitoba Health Insurance Registry to identify status First Nations people. }\end{array}$ \\
\hline Note: CABG = coronary artery bypass graft, ICD = International Classification of Diseases, PCI = percutaneous coronary intervention.
\end{tabular}

random selection began with identifying First Nations patients undergoing index angiography and then matching 2 non-First Nations patients undergoing index angiography, following the cohort criteria outlined above. The administrative data also supplied 2 baseline characteristic variables: income quintile and Charlson Comorbidity Index. ${ }^{17,18}$

Collection of data from the medical charts was done by randomly selecting matched pairs derived by MCHP and using a standardized tool previously pilot tested by an experienced cardiac clinical nurse specialist (K.T.). The remaining baseline characteristics were obtained from this data source, which included coronary artery disease risk factors (i.e., family history of coronary artery disease, obesity, current and past smoking history, diabetes, insulin use, hypertension and dyslipidemia), comorbid conditions (i.e., prior acute MIs, stroke, congestive heart failure, peripheral vascular disease and cancer) and indication prompting angiography referral (i.e., ST-elevation MI (STEMI), non-STelevation MI, unstable angina, stable angina or to rule out coronary artery disease). Each variable was recorded as a dichotomous variable indicating its absence or presence. If the information regarding a particular variable was not captured in the medical chart (e.g., dyslipidemia), it was assumed that patient did not have the variable of interest and they were recorded as such.

Chart audits were completed by an undergraduate nursing student research assistant with Indigenous ancestry; K.T. guided data extraction by initially being present during chart audits and then remained available for questions from the research assistant, along with performing random reviews for accuracy. Retrieved chart data were entered into a studyspecific database by L.D., which served as a final check for completeness of chart audit data.
For this study, severity of coronary artery disease was measured using the SYNTAX Score, which is a clinical risk-assessment tool used for diagnostic purposes in cardiac care. Scores are calculated based on the number of lesions and their functional impact, location and complexity, with higher scores representing more complex coronary artery disease. ${ }^{19}$ Calculation of the SYNTAX Score considers each lesion with greater than $50 \%$ occlusion in vessels at least $1.5 \mathrm{~mm}$ in diameter, which follows the modified guideline on coronary artery tree segment classification from the American Heart Association. ${ }^{19,20}$ Although this risk-assessment tool was developed to grade anatomic complexity for decisions about revascularization treatment, research shows it is a valid prognostic indicator of major adverse coronary and cerebrovascular events among various clinical populations, including those with multivessel disease, left main coronary artery disease, STEMI and acute coronary syndrome. ${ }^{21-25}$ Angiography images for our matched pairs were reviewed by either a cardiologist (T.N.) or an interventional cardiologist (B.E.), who calculated the SYNTAX Score for each patient.

\section{Outcomes}

Primary health outcomes were all-cause and cardiovascularrelated mortality. Secondary health outcomes were hospital admissions for any cause, acute MIs, congestive heart failure, ischemic heart disease and stroke. Percutaneous coronary intervention and CABG procedures, including those which were part of the index hospital admission, were also examined. The follow-up period for each outcome began on the index angiography date and ended 5 years later or on Mar. 31, 2018 (study termination date), whichever occurred first. 


\section{Statistical analysis}

To compare the extent of coronary artery disease between First Nations and non-First Nations groups, the median results from the SYNTAX Score and interquartile ranges (IQRs) were tested for differences using a Wilcoxon signedrank test. Patients were also categorized based on their SYNTAX Score result; patients with "normal coronary arteries" $($ SYNTAX Score $=0)$ were assigned to category I, and patients with a positive SYNTAX Score (i.e., any nonzero score) were assigned to categories II, III or IV, which were defined by SYNTAX Score tertiles. ${ }^{26}$ Distribution of First Nations and non-First Nations patients in SYNTAX Score categories were compared using a $\chi^{2}$ test for independence.

Inverse probability of treatment weighting (IPTW) was applied to the matched cohorts during the analysis of primary and secondary outcomes and used to estimate average treatment effect. Given our sample size, the IPTW accommodated the number of baseline characteristics collected from the administrative data sets and medical charts that might influence the outcomes. The IPTW values were based on an estimated probability of being First Nations using a logistic regression model that included each of the baseline characteristics; First Nations patients were given a weight of 1 and non-First Nations patients a weight that represented the odds of being First Nations. ${ }^{27,28}$ Standardized differences were used to compare each of the baseline variables between First Nations and non-First Nations groups in the unweighted and weighted samples. A difference greater than $10 \%$ suggested an imbalance between the First Nations and non-First Nations groups. ${ }^{26}$

The proportions of patients in each group who experienced the primary and secondary outcomes were compared using $\chi^{2}$ tests. Cox proportional hazards models were used to estimate the strength of association between First Nations status and each outcome in the weighted sample. An unadjusted model and 2 adjusted models were assessed for mortality and hospital admission outcomes. Both adjusted models controlled for a time-varying composite variable indicating whether the patient underwent a PCI or CABG during the follow-up period, and the second model also included the SYNTAX Score as a continuous variable. When PCI or CABG were assessed as outcomes, the time-varying revascularization variable was not included in the models. To account for the correlated failure times within matched pairs, we used a robust sandwich covariance estimate in the survival analysis. ${ }^{29}$ Estimates are presented as hazard ratios (HRs) and 95\% confidence intervals (CIs). Statistical significance for all tests was set at $p=0.05$. All analysis was done on the secure server at MCHP, using SAS statistical analysis software, version 9.4 (SAS Institute Inc., 2016).

\section{Ethics approval}

Study approval was obtained from the University of Manitoba's Education and Nursing Research Ethics Board, the Manitoba Health Information Privacy Committee and the FNHSSM's Health Information Research Governance Committee.

\section{Results}

A final study cohort included 277 matched pairs of First Nations and non-First Nations patients (Figure 1). Baseline characteristics of the matched cohort, which includes First Nations patients $(n=277)$ and non-First Nations patients $(n=$ 277), are shown in Table 2. Mean age was 56.0 (standard deviation 11.7 ) years, $57.0 \%$ of the patients were male, $52.7 \%$ resided in urban areas and distributions of patients according to index date were similar between groups.

Standardized differences in the unweighted sample indicate that the proportion of patients reporting a family history of coronary artery disease was lower in the First Nations group than in the non-First Nations group, and significantly higher proportions of First Nations patients were current smokers and past smokers, and had diabetes, hypertension and dyslipidemia. First Nations patients also had more comorbidities and had a higher mean Charlson Comorbidity Index score. The proportions of obese patients were higher in the First Nations group; however, the average body mass index scores were similar. A higher proportion of First Nations patients were in the lowest

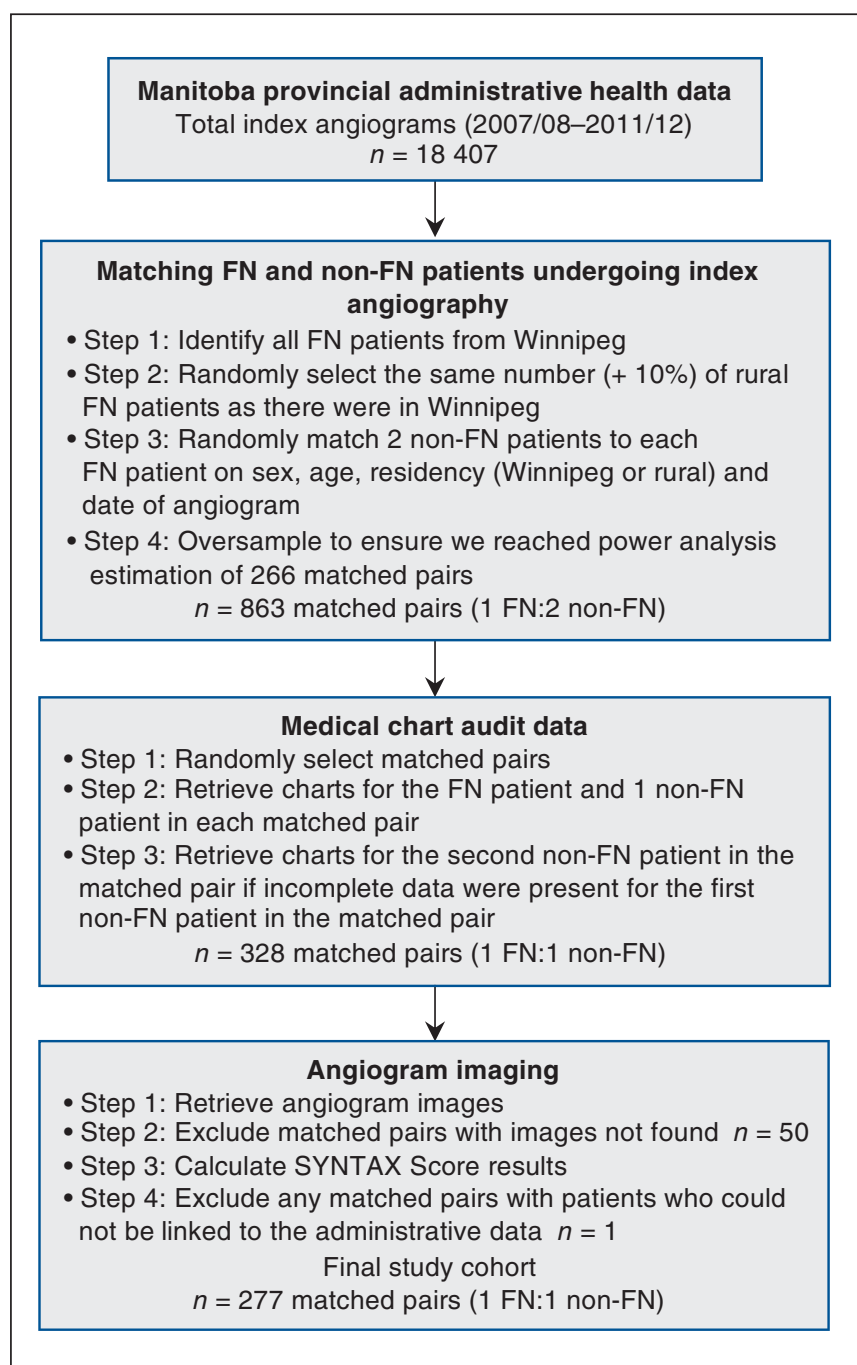

Figure 1: First Nations (FN) and non-FN matched cohort sampling. 
Table 2: Comparison of baseline characteristics between First Nations and non-First Nations patients undergoing index angiography, in the unweighted and weighted matched cohorts

\begin{tabular}{|c|c|c|c|c|}
\hline \multirow[b]{2}{*}{ Characteristic } & \multicolumn{2}{|c|}{ No. $(\%)$ of patients* } & \multicolumn{2}{|c|}{ Standardized difference } \\
\hline & $\begin{array}{l}\text { First Nations } \\
\quad n=277\end{array}$ & $\begin{array}{c}\text { Non-First } \\
\text { Nations } \\
n=277\end{array}$ & Unweighted & Weighted \\
\hline \multicolumn{5}{|l|}{ Matching variables } \\
\hline Age, yr, mean \pm SD & $55.8 \pm 11.7$ & $56.0 \pm 11.7$ & 0.013 & 0.049 \\
\hline Sex, male & $158(57.0)$ & $158(57.0)$ & 0.000 & 0.000 \\
\hline Urban (Winnipeg) & $146(52.7)$ & $146(52.7)$ & 0.000 & 0.000 \\
\hline \multicolumn{5}{|l|}{ Year of angiography } \\
\hline 2008 & $45(16.3)$ & $42(15.2)$ & 0.030 & 0.106 \\
\hline 2009 & $70(25.3)$ & $69(24.9)$ & 0.008 & 0.009 \\
\hline 2010 & $65(23.5)$ & $71(25.6)$ & 0.050 & 0.059 \\
\hline 2011 & $74(26.7)$ & $72(26.0)$ & 0.016 & 0.066 \\
\hline 2012 & $23(8.3)$ & $23(8.3)$ & 0.000 & 0.095 \\
\hline \multicolumn{5}{|l|}{ Conventional risk-factor variables } \\
\hline $\begin{array}{l}\text { Family history of coronary artery } \\
\text { disease }\end{array}$ & $87(31.4)$ & $119(43.0)$ & 0.241 & 0.056 \\
\hline Obesity & $140(50.5)$ & $122(44.0)$ & 0.130 & 0.060 \\
\hline $\mathrm{BMI}$, mean $\pm \mathrm{SD}$ & $30.5 \pm 6.2$ & $30.4 \pm 6.8$ & 0.015 & 0.053 \\
\hline Current smoker & $138(49.8)$ & $88(31.8)$ & 0.374 & 0.074 \\
\hline Past smoker (ever) & $215(77.6)$ & $157(56.7)$ & 0.457 & 0.049 \\
\hline Diabetes & $151(54.5)$ & 48 (17.3) & 0.841 & 0.075 \\
\hline Insulin & $56(20.2)$ & $16(5.8)$ & 0.440 & 0.079 \\
\hline Hypertension & $188(67.9)$ & $151(54.5)$ & 0.277 & 0.093 \\
\hline Dyslipidemia & $160(57.8)$ & $124(44.8)$ & 0.262 & 0.140 \\
\hline \multicolumn{5}{|l|}{ Income quintile } \\
\hline 1 (lowest) & $156(56.3)$ & $46(16.6)$ & 0.906 & 0.134 \\
\hline 2 & $43(15.5)$ & $51(18.4)$ & 0.077 & 0.013 \\
\hline 3 & $28(10.1)$ & $59(21.3)$ & 0.311 & 0.138 \\
\hline 4 & $40(14.4)$ & $53(19.1)$ & 0.126 & 0.060 \\
\hline 5 (highest) & $10(3.6)$ & $68(24.5)$ & 0.631 & 0.023 \\
\hline Charlson Comorbidity Index score & $2.3 \pm 2.4$ & $0.9 \pm 1.2$ & 0.687 & 0.168 \\
\hline Previous MI & $28(10.1)$ & $20(7.2)$ & 0.103 & 0.157 \\
\hline Congestive heart failure & $41(14.8)$ & $29(10.5)$ & 0.131 & 0.011 \\
\hline Cancer & $S$ & $14(5.1)$ & 0.179 & 0.012 \\
\hline Peripheral vascular disease & $29(10.5)$ & $10(3.6)$ & 0.271 & 0.077 \\
\hline Stroke & $23(8.3)$ & $12(4.3)$ & 0.164 & 0.125 \\
\hline \multicolumn{5}{|l|}{ Indication for angiography } \\
\hline Rule out coronary artery disease & $64(23.1)$ & $56(20.2)$ & 0.070 & 0.027 \\
\hline STEMI & $64(23.1)$ & 55 (19.9) & 0.079 & $<0.000$ \\
\hline NSTEMI & $108(39.0)$ & $98(35.4)$ & 0.075 & 0.017 \\
\hline Unstable angina & $17(6.1)$ & $18(6.5)$ & 0.015 & 0.053 \\
\hline Angina & $33(11.9)$ & $60(21.7)$ & 0.263 & 0.009 \\
\hline
\end{tabular}




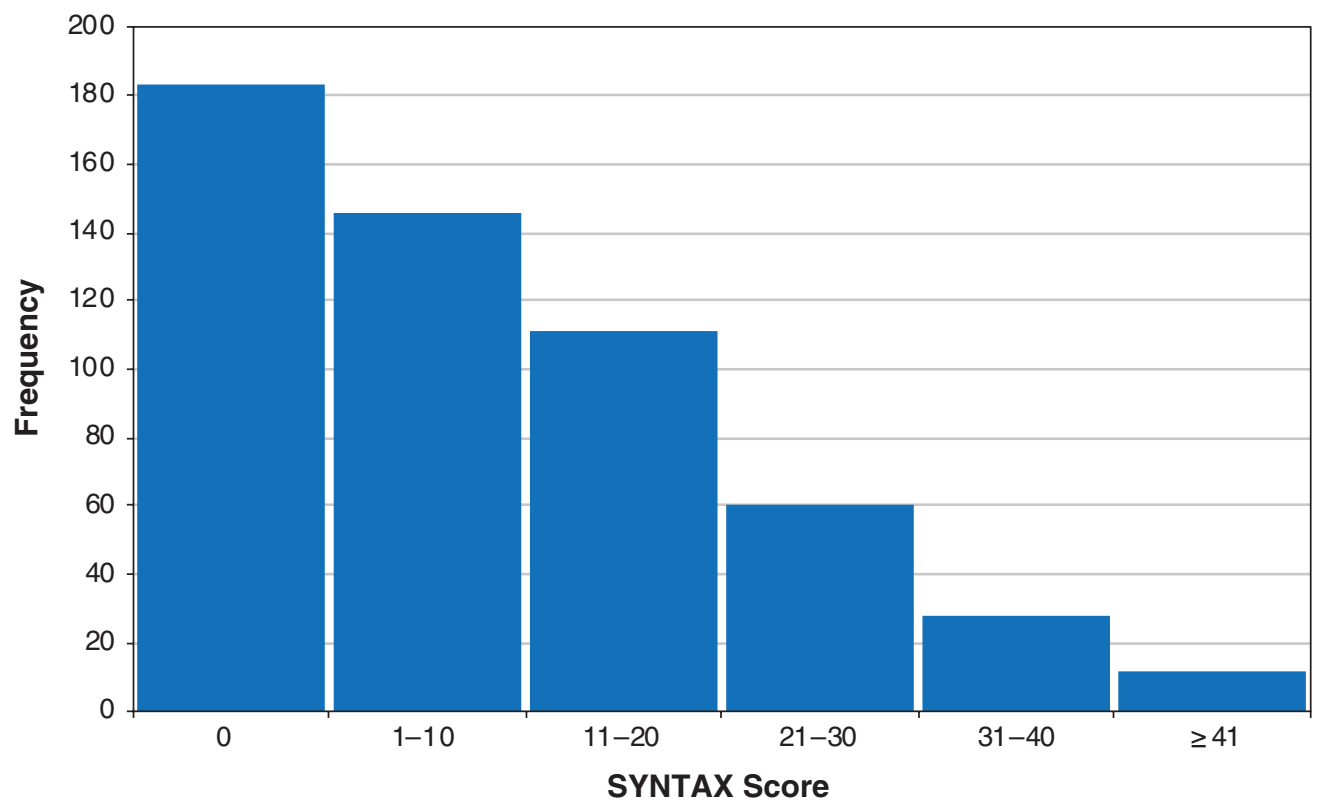

Figure 2: Histogram of SYNTAX Score results for full index angiography cohort. Positive SYNTAX Score results grouped by 10-point increments.

income quintile, and lower proportions were in the highest quintile than non-First Nations patients. Lastly, a lower proportion of First Nations patients for referrals for angiography were due to stable angina compared with the non-First Nations group; however, no significant differences were observed for any of the other indications for angiography.

Weighted standardized differences show more balance between group baseline characteristics. Among the 7 characteristics exceeding the $10 \%$ threshold, only previous MI and the proportion of patients who underwent angiography in 2008 were higher in the weighted analysis than in the unweighted analysis.

\section{SYNTAX Score}

Overall, 182 patients (32.9\%) had a SYNTAX Score of 0 (category I), and the frequency of patients with a higher SYNTAX Score decreased steadily (Figure 2): $128(23.1 \%)$ patients were in category II (scores 1 to 9), 125 (22.6\%) were in category III (scores > 9 to 18 ) and 119 (21.5\%) were in category IV (scores $>18)$.

The median SYNTAX Score results of 8.0 (IQR 18.0) in the First Nations group and 6.0 (IQR 16.0) in the non-First Nations group were not significantly different. The highest proportions of patients were in category I (30.3\% for the First Nations group and $35.4 \%$ for the non-First Nations group, with no significant differences in the distributions of patients in the SYNTAX Score categories between First Nations and non-First Nations groups (Figure 3A). Distributions of patients in the SYNTAX Score categories were also similar between First Nations and non-First Nations patients in the analysis stratified by urban/rural status (Figures 3B and 3C).

\section{Outcomes}

The proportions of all-cause mortality, cardiovascular mortality, all-cause hospital admission, acute MI hospital admission and ischemic heart disease hospital admission were significantly higher in the First Nations group than in the non-First Nations group (Table 3). However, in the weighted sample, the crude and adjusted risk for all-cause mortality and cardiovascular mortality were not significantly different between First Nations and non-First Nations groups.

Among the secondary outcomes, after controlling for revascularizations and SYNTAX Score results, only the risk for acute MI hospital admission (HR 3.03, 95\% CI 1.40-6.55) and congestive heart failure hospital admission (HR 3.84, 95\% CI 1.37-10.78) were higher in the First Nations group than in the non-First Nations group (Table 3). There were no significant between-group differences in the likelihood of all-cause mortality or in patients undergoing PCI or CABG in any of the models.

\section{Interpretation}

Our retrospective study of matched First Nations and nonFirst Nations adult patients showed no significant differences in severity of coronary artery disease as measured by the SYNTAX Score, despite a higher proportion of First Nations patients presenting with risk factors for coronary artery disease at the time of diagnostic angiography. Health outcomes were significantly different between groups, with a proportionally higher number of First Nations patients who died or were admitted to hospital during a 5-year follow-up period in comparison to non-First Nations patients. However, these 
A

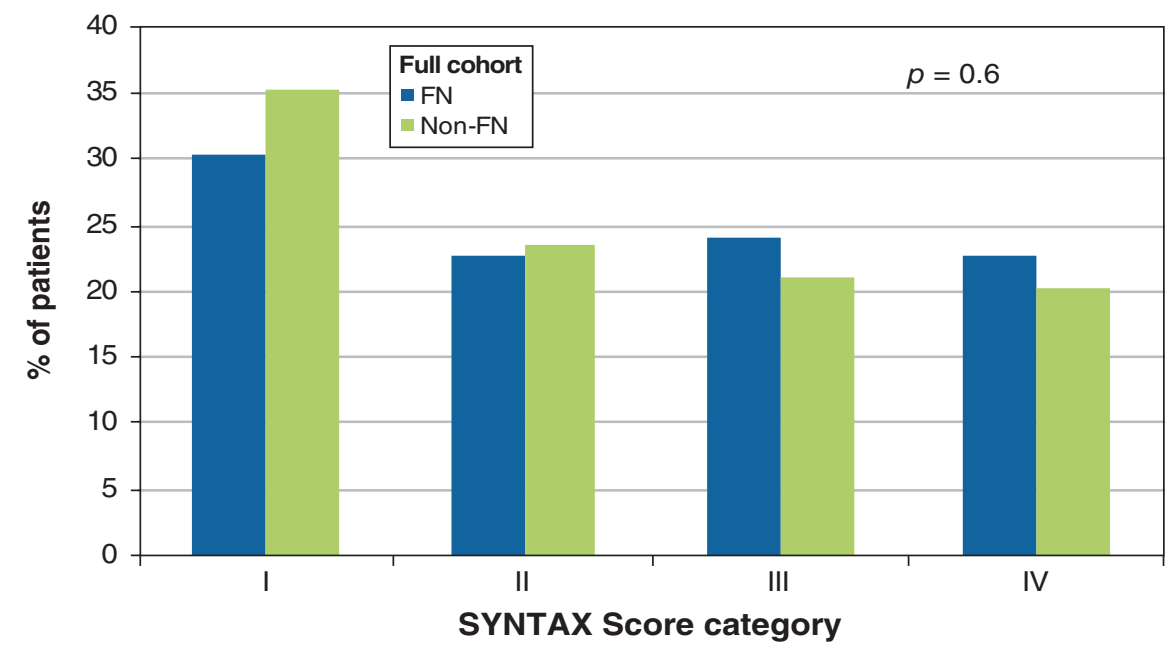

B

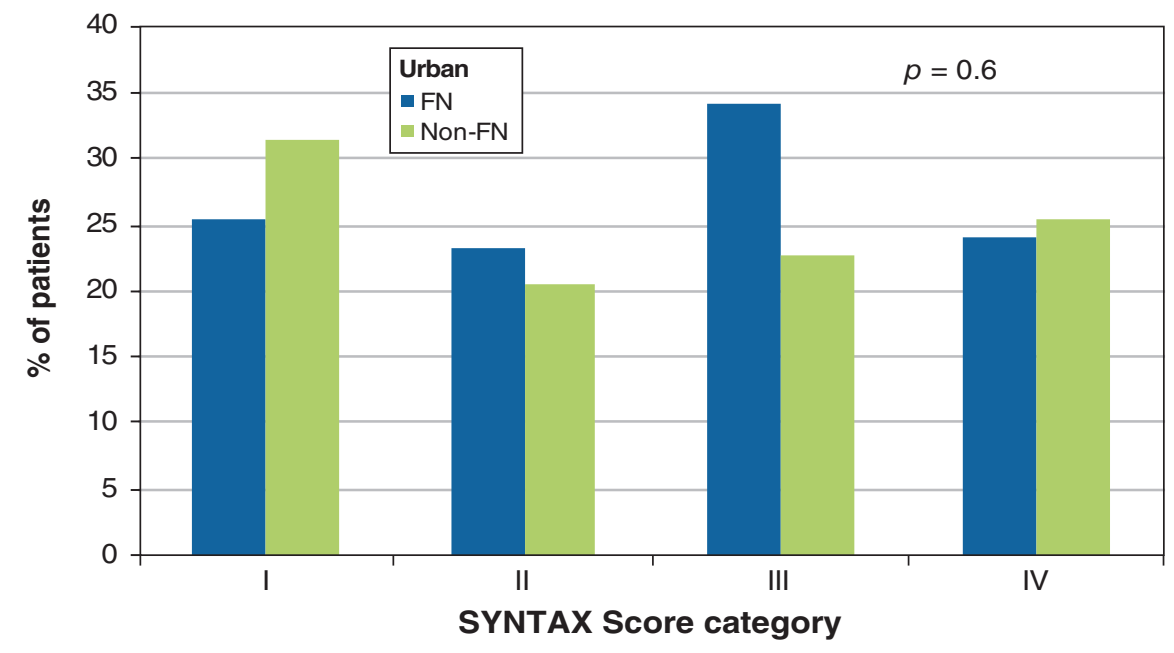

C

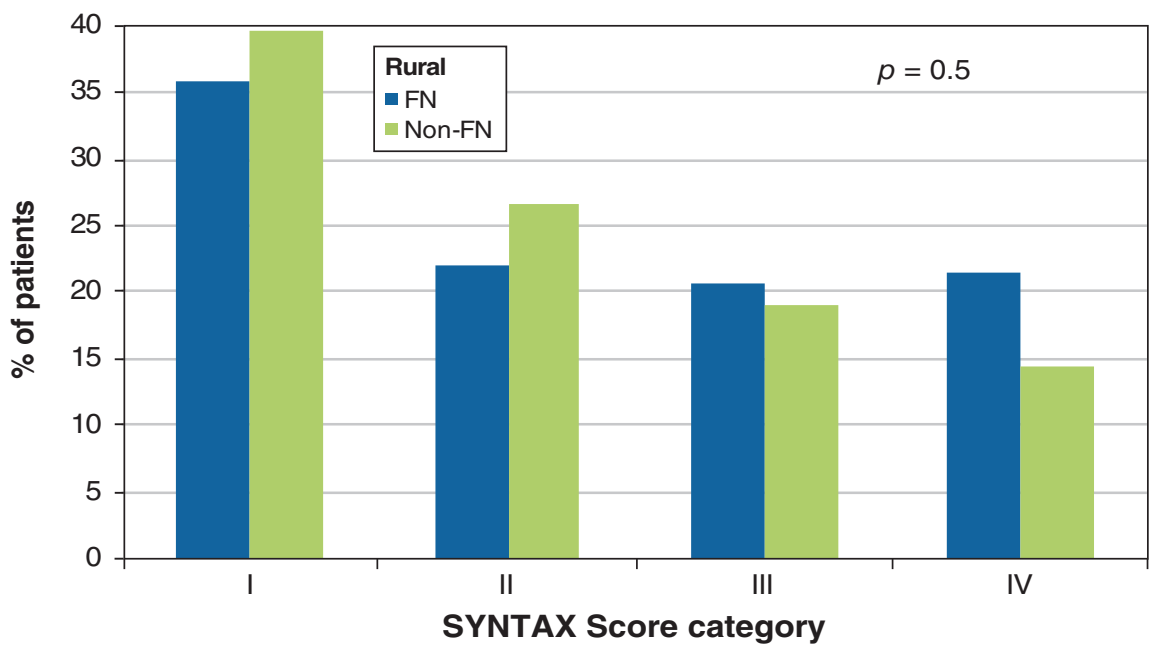

Figure 3: Percentage of First Nations (FN) and non-FN patients in each of the SYNTAX Score categories. SYNTAX Score category I = a score of 0 , category II = a score of 1 to 9 , category III = a score of $\geq 9$ to 18 , category IV = a score of $\geq 18$. 


\begin{tabular}{|c|c|c|c|c|c|}
\hline \multirow[b]{2}{*}{ Variable } & \multicolumn{2}{|c|}{ No. $(\%)$ of patients } & \multicolumn{3}{|c|}{ Hazard ratio $(95 \% \mathrm{Cl})$} \\
\hline & $\begin{array}{l}\text { First } \\
\text { Nations } \\
n=277\end{array}$ & $\begin{array}{l}\text { Non-First } \\
\text { Nations } \\
n=277\end{array}$ & Crude & Adjusted model 1 & Adjusted $†$ model 2 \\
\hline All-cause mortality $\ddagger$ & $73(26.4)$ & $26(9.4)$ & $1.43(0.65-3.16)$ & $1.43(0.64-3.20)$ & $1.42(0.64-3.14)$ \\
\hline Cardiovascular mortality $\ddagger$ & $36(13.0)$ & $13(4.7)$ & $2.66(0.85-8.30)$ & $2.73(0.87-8.51)$ & $2.64(0.86-8.10)$ \\
\hline All-cause hospital admission $\ddagger$ & $214(77.3)$ & $145(52.3)$ & $1.41(0.99-2.00)$ & $1.41(0.99-2.00)$ & $1.39(0.97-1.99)$ \\
\hline Acute Ml‡ & $38(13.7)$ & $18(6.5)$ & $3.05(1.45-6.41)$ & $3.01(1.42-6.39)$ & $3.03(1.40-6.55)$ \\
\hline Congestive heart failure & $16(5.8)$ & $9(3.2)$ & $3.86(1.37-10.83)$ & $3.86(1.38-10.82)$ & $3.84(1.37-10.78)$ \\
\hline Ischemic heart disease $\neq$ & $80(28.9)$ & $53(19.1)$ & $1.77(0.99-3.15)$ & $1.75(0.99-3.12)$ & $1.77(0.99-3.18)$ \\
\hline Stroke & $11(4.0)$ & $6(2.2)$ & $3.06(0.82-11.44)$ & $3.12(0.83-11.67)$ & $3.07(0.81-11.65)$ \\
\hline $\mathrm{PCl}$ & $117(42.2)$ & $118(42.6)$ & $0.91(0.64-1.30)$ & & $0.89(0.63-1.25)$ \\
\hline CABG§ & $51(18.4)$ & $35(12.6)$ & $1.54(0.74-3.19)$ & & $1.29(0.61-2.70)$ \\
\hline \multicolumn{6}{|c|}{$\begin{array}{l}\text { Note: } \mathrm{CABG}=\text { coronary artery bypass graft, } \mathrm{Cl}=\text { confidence interval, } \mathrm{MI}=\text { myocardial infarction, } \mathrm{PCl}=\text { percutaneous coronary intervention. } \\
\text { *Adjusted for time-varying composite revascularization variable. } \\
+ \text { Adjusted for time-varying composite revascularization variable and SYNTAX Score. } \\
\ddagger p=0.05 \text { as assessed by } \chi^{2} \text {. } \\
\text { §Adjusted models do not include time-varying composite revascularization variable. }\end{array}$} \\
\hline
\end{tabular}

differences in mortality and all-cause hospital admission risk were no longer present after controlling for coronary artery disease risk factors using inverse probability of treatment weights. Clinically, these findings suggest the need to focus on risk factors for coronary artery disease and lowering rates among First Nations populations, which requires a critical look at underlying factors influencing group differences rather than a focus only on individuals. ${ }^{30-37}$

Similarities in SYNTAX Score between First Nations and non-First Nations groups were unexpected, given that higher scores are predictive of future adverse cardiovascular events $^{21-25,38}$ and previous research, along with our findings, suggests that First Nations populations tend to experience higher rates of those events. ${ }^{6,9-11,13,14}$ However, interethnic differences in SYNTAX Score results have been previously reported. Among patients with STEMI, higher SYNTAX Score results were reported in Chinese patients compared with their White counterparts, despite a lower prevalence of risk factors for coronary artery disease. ${ }^{39}$ Conversely, South Asian patients with stable coronary artery disease had lower SYNTAX Score results than White patients, despite a higher prevalence of risk factors. ${ }^{39}$ Our study has identified a third pattern in which First Nations and non-First Nations patients undergoing angiography appear to access diagnosis at a similar point in terms of coronary artery disease complexity (SYNTAX Score), but First Nations patients present with more risk factors for coronary artery disease. Further investigation to explore this pattern will extend our understanding of different clinical presentations at time of diagnosis and inform potential nuanced treatment plans for First Nations patients.

Proportionally, First Nations patients undergoing angiography in our study experienced an increased risk of cardiac mortality and repeat hospital admissions, which is consistent with reported overall health disparities among First Nations and non-First Nations people. ${ }^{40}$ Our findings also suggest that differences in risk factors for coronary artery disease at presentation largely explain reported cardiac-related health outcome disparities, which, in turn, supports a need to decrease risk factors for coronary artery disease among First Nations populations.

Avoiding pitfalls of exclusively adopting a focus on individual lifestyle factors, while ignoring distal determinants influencing the daily life and health of Indigenous people is imperative. ${ }^{30}$ Current-day influences, including living within impoverished communities at a distance from large cities, make affordable, healthy diets nearly unattainable for many Manitoba First Nations, contributing substantially to weightrelated risk factors. ${ }^{41}$ Historical and persistent colonizing practices and policies have resulted in a loss of Indigenous Peoples' cultures, languages, lands and traditions, and all have been shown to underlie health inequities reported among Indigenous people. ${ }^{30-33,36,41}$ Intergenerational historic trauma, along with current-day trauma and stress caused by colonizing practices, and racism faced by Indigenous people directly affect cardiovascular health. ${ }^{34}$

Ignoring these historical and ongoing contexts will result in dismissing the fact that the capacity to make healthful choices is not equal among all people. ${ }^{34}$ Although certain behavioural characteristics are associated with improved cardiovascular health, Indigenous people face structural systemic barriers $^{32}$ that need to be addressed to reduce cardiovascular disparities. Future research into risk factors for coronary artery disease and distal determinants of health among Indigenous populations is warranted; in particular, strategic approaches developed and based on specific needs, strengths, and social determinants among communities are imperative. ${ }^{37}$ 


\section{Limitations}

Findings from this retrospective chart review come with method-based limitations. With chart audits, ${ }^{42}$ missing data and the quality of data recorded by clinicians within the context of health care delivery and not research are inherent limitations. There was no consistent pattern of more missing data in either group, though there remains an inherent risk of bias. The quality of data recorded in the clinical charts used in this study was outside of our control, but we based our analysis on data that were used to inform care of the study patients, the best available data for retrospective study of health care and health outcomes. Data from the charts were not double-coded, but we employed methods to check and ensure the quality of data extracted by the study coder independently. Limited resources influenced a decision to use 1:1 matching, which may have affected the precision of our findings. ${ }^{43}$

There are also 3 measurement limitations worth mentioning. First, although the SYNTAX Score provides a quantifiable measure of coronary artery disease complexity and risk associated with revascularization strategies, it may lack nuanced reflection of coronary artery disease severity or overall atherosclerotic burden. Given that the SYNTAX Score algorithm does not consider percent diameter of stenosis, ${ }^{19}$ there may be differences in the degree of arterial narrowing between populations. Second, the assessment of coronary artery disease risk factors included whether they were present in the chart. It is possible that biomarker levels for certain risk factors may be different between populations or that a different strength of association between biomarker levels and outcomes exist among First Nations and nonFirst Nations populations. Finally, unmeasured confounders may also have influenced the results, including patient preferences regarding treatments, physical activity levels, accessibility to outpatient cardiac rehabilitation services (including travel and accommodation costs), food availability and consumption patterns, practitioner implicit bias, cultural safety of care and wait times.

\section{Conclusion}

Once patients were receiving care in the cardiac care system, differences in presenting coronary artery disease risk factors explained between-group health outcome differences. Although this finding is not surprising, translating this finding into clinical and policy settings demands a willingness to look beyond understanding health as a function of individuals and their behaviours. Addressing root causes underlying coronary artery disease demands seeing daily inequities faced by Indigenous people within our society and acting to diminish underlying structures, such as access-to-care barriers and systemic racism. Prevention strategies require decolonization strategies, including efforts toward truth and reconciliation, and integration of traditional wellness knowledge and practices. A focus solely on individuals and lifestyles will fail to achieve the desired outcome of improved cardiac health among First Nations and all Indigenous people.

\section{References}

1. Tu JV, Nardi L, Fang J, et al.; Canadian Cardiovascular Outcomes Research Team. National trends in rates of death and hospital admissions related to acute myocardial infarction, heart failure and stroke, 1994-2004. CMA7 2009;180:E118-25.

2. Critchley JA, Capewell S. Mortality risk reduction associated with smoking cessation in patients with coronary heart disease: a systematic review. $7 A M A$ 2003;290:86-97.

3. Kohl HW III. Physical activity and cardiovascular disease: evidence for a dose response. Med Sci Sports Exerc 2001;33(Suppl):S472-83.

4. Ford ES, Ajani UA, Croft JB, et al. Explaining the decrease in US deaths from coronary disease, 1980-2000. N Engl F Med 2007;356:2388-98.

5. Wijeysundera HC, Machado M, Farahati F, et al. Association of temporal trends in risk factors and treatment uptake with coronary heart disease mortality, 1994-2005. FAMA 2010;303:1841-7.

6. Young TK. Cardiovascular health among Canada's Aboriginal populations: a review. Heart Lung Circ 2012;21:618-22.

7. Anand SS, Yusuf S, Jacobs R, et al. Risk factors, atherosclerosis, and cardiovascular disease among Aboriginal people in Canada: the Study of Health Assessment and Risk Evaluation in Aboriginal Peoples (SHARE-AP). Lancet 2001;358:1147-53.

8. Shah BR, Hux JE, Zinman B. Increasing rates of ischemic heart disease in the native population of Ontario, Canada. Arch Intern Med 2000;160:1862-6.

9. Tjepkema M, Wilkins R, Goedhuis N. Cardiovascular disease mortality among First Nations people in Canada, 1991-2001. Chronic Dis Inj Can 2012;32:200-7.

10. Hospital care for heart attacks among First Nation, Inuit and Métis. Ottawa: Canadian Institute for Health Information; 2013.

11. Bresee LC, Knudtson ML, Zhang J, et al.; Alberta Kidney Disease Network $(\mathrm{AKDN})$ and the Alberta Provincial Project for Outcome Assessment in Coronary Heart Disease (APPROACH). Likelihood of coronary angiography among First Nations patients with acute myocardial infarction. CMA7 2014;186:E372-80.

12. Schultz ASH, Dahl L, McGibbon E, et al. Index coronary angiography use in Manitoba, Canada: a population-level descriptive analysis of First Nations and non-First Nations recipients. BMF Open 2018;8:e20856.

13. Schultz A, Dahl L, McGibbon E, et al. Health outcome and follow-up care differences between First Nation and non-First Nation coronary angiogram patients: a retrospective cohort study. Can 7 Cardiol 2018;34:1333-40.

14. Dahl L, Schultz AS, McGibbon E, et al. Cardiovascular medication use and long-term outcomes of First Nations and non-First Nations patients following diagnostic angiography: a retrospective cohort study. 7 Am Heart Assoc 2019;8:e012040.

15. Registered Indian population by sex and residence 2016. Ottawa: Indigenous Services Canada; 2018. Available: www.aadnc-aandc.gc.ca/DAM/DAM-INTER-HQ-AI/ STAGING/texte-text/registered_indian_2016_main_1526060531549_eng.pdf (accessed 2020 June 23).

16. Lavoie JG, Kaufert J, Browne AJ, et al. Negotiating barriers, navigating the maze: First Nation peoples' experience of medical relocation. Can Public Adm 2015;58:295-314. doi: 10.1111/capa.12111.

17. Deyo RA, Cherkin DC, Ciol MA. Adapting a clinical comorbidity index for use with ICD-9-CM administrative databases. F Clin Epidemiol 1992;45:613-9.

18. Quan H, Sundararajan V, Halfon P, et al. Coding algorithms for defining comorbidities in ICD-9-CM and ICD-10 administrative data. Med Care 2005;43:1130-9.

19. Sianos G, Morel M-A, Kappetein AP, et al. The SYNTAX Score: an angiographic tool grading the complexity of coronary artery disease. EuroIntervention 2005;1:219-27.

20. Austen WG, Edwards JE, Frye RL, et al. A reporting system on patients evaluated for coronary artery disease. Report of the Ad Hoc Committee for Grading of Coronary Artery Disease, Council on Cardiovascular Surgery, American Heart Association. Circulation 1975;51:5-40.

21. Serruys PW, Morice M-C, Kappetein AP, et al. Percutaneous coronary intervention versus coronary-artery bypass grafting for severe coronary artery disease. N Engl 7 Med 2009;360:961-72.

22. Mohr FW, Morice M-C, Kappetein AP, et al. Coronary artery bypass graft surgery versus percutaneous coronary intervention in patients with three-vessel disease and left main coronary disease: 5-year follow-up of the randomised, clinical SYNTAX trial. Lancet 2013;381:629-38.

23. Capodanno D, Di Salvo ME, Cincotta G, et al. Usefulness of the SYNTAX score for predicting clinical outcome after percutaneous coronary intervention of unprotected left main coronary artery disease. Circ Cardiovasc Interv 2009;2:302-8.

24. Palmerini T, Genereux P, Caixeta A, et al. Prognostic value of the SYNTAX score in patients with acute coronary syndromes undergoing percutaneous coronary intervention: analysis from the ACUITY (Acute Catheterization and Urgent Intervention Triage StrategY) trial. 7 Am Coll Cardiol 2011;57: 2389-97.

25. Magro M, Nauta S, Simsek C, et al. Value of the SYNTAX score in patients treated by primary percutaneous coronary intervention for acute ST-elevation myocardial infarction: The MI SYNTAXscore study. Am Heart 7 2011; 161:771-81. 
26. Austin PC. Balance diagnostics for comparing the distribution of baseline covariates between treatment groups in propensity-score matched samples. Stat Med 2009;28:3083-107.

27. Austin PC. An introduction to propensity score methods for reducing the effects of confounding in observational studies. Multivariate Behav Res 2011;46:399-424.

28. Austin PC. Variance estimation when using inverse probability of treatment weighting (IPTW) with survival analysis. Stat Med 2016;35:5642-55.

29. Lee EW, Wei LJ, Amato DA, et al. Cox-type regression analysis for large numbers of small groups of correlated failure time observations. In: Klein JP, Goel PK, editors. Survival Analysis: State of the Art. Nato Science (Series E: Applied Sciences). Vol 211. Berlin (Germany): Springer, Dordrecht; 1992:237-47.

30. Adelson N. The embodiment of inequity: health disparities in Aboriginal Canada. Can 7 Public Health 2005;96(Suppl 2):S45-61.

31. Czyzewski K. Colonialism as a broader social determinant of health. International Indigenous Policy Fournal 2011;2:5. doi: 10.18584/iipj.2011.2.1.5.

32. Greenwood M, de Leeuw S, Lindsay NM, et al. Determinants of Indigenous Peoples' bealth in Canada: beyond the social. Toronto: Canadian Scholars' Press, 2015.

33. Katz A, Enns J, Kinew KA. Canada needs a holistic First Nations health strategy. CMA7 2017;189:E1006-7.

34. McGibbon E, Waldron I, Jackson J. The social determinants of cardiovascular disease: time for a focus on racism. Divers Equal Health Care 2013;10:139-42.

35. Reading J. The crisis of chronic disease among Aboriginal peoples: a challenge for public bealth, population bealth and social policy. Victoria: Centre for Aboriginal Health Research, University of Victoria; 2009.

36. Richmond CAM, Ross NA. The determinants of First Nation and Inuit health: a critical population health approach. Health Place 2009;15:403-11.

37. Tobe SW, Maar M, Roy MA, et al. Preventing cardiovascular and renal disease in Canada's Aboriginal populations. Can 7 Cardiol 2015;31:1124-9.

38. Garg S, Sarno G, Serruys PW, et al.; STRATEGY and MULTISTRATEGY Investigators. Prediction of 1-year clinical outcomes using the SYNTAX score in patients with acute ST-segment elevation myocardial infarction undergoing primary percutaneous coronary intervention: a substudy of the STRATEGY (Single High-Dose Bolus Tirofiban and Sirolimus-Eluting Stent Versus Abciximab and Bare-Metal Stent in Acute Myocardial Infarction) and MULTISTRATEGY (Multicenter Evaluation of Single HighDose Bolus Tirofiban Versus Abciximab With Sirolimus-Eluting Stent or Bare-Metal Stent in Acute Myocardial Infarction Study) trials. 7 ACC Cardiovasc Interv 2011;4:66-75.

39. Gijsberts CM, Seneviratna A, Hoefer IE, et al. Inter-ethnic differences in quantified coronary artery disease severity and all-cause mortality among Dutch and Singaporean percutaneous coronary intervention patients. PLoS One 2015;10:e0131977.

40. Martens PJ, Sanderson D, Jebamani L. Health services use of Manitoba First Nations people: Is it related to underlying need? Can 7 Public Health 2005;96(Suppl 1):S39-44.

41. Burnett K, Hay T, Skinner K. Government policy, food insecurity, and Indigenous Peoples in northern Canada. In: K. Burnett, G. Read, editors, Aboriginal history: a reader. Don Mills (ON): Oxford University Press; 2016.

42. Donabedian A. An introduction to quality assurance in bealth care. Oxford (UK): Oxford University Press; 2002.

43. Austin PC. Statistical criteria for selecting the optimal number of untreated subjects matched to each treated subject when using many-to-one matching on the propensity score. Am F Epidemiol 2010;172:1092-7.

Affiliations: College of Nursing (Schultz, Dahl, Sawatzky, Sinclaire), Rady Faculty of Health Sciences, University of Manitoba; St. Boniface Hospital Research Centre (Schultz, Dahl, Sawatzky, Sinclaire), Winnipeg, Man.; Rankin School of Nursing, Faculty of Health Sciences (McGibbon), St. Francis Xavier University, Antigonish, NS; Department of History (Brownlie), Faculty of Arts, University of Manitoba;
First Nations, Métis and Inuit Health (Cook), Max Rady College of Medicine, Rady Faculty of Health Sciences, University of Manitoba; Cardiac Sciences Program, St. Boniface Hospital (Elbarouni, Nguyen, Throndson); Max Rady College of Medicine (Elbarouni, Nguyen), Rady Faculty of Health Sciences, University of Manitoba; Manitoba Centre for Health Policy (Katz, Fransoo, Prior), and Max Rady College of Medicine (Katz), Rady Faculty of Health Sciences, University of Manitoba, Winnipeg, Man.

Contributors: Annette Schultz contributed to the conceptualization, funding acquisition, investigation, methodology, project administration, resources and supervision. Lindsey Dahl contributed to the conceptualization, investigation, methodology and project administration. Elizabeth McGibbon, Jarvis Brownlie, Catherine Cook, Alan Katz, Jo-Ann Sawatzky and Karen Throndson contributed to the conceptualization and funding acquisition. Basem Elbarouni, Thang Nguyen and Randy Fransoo contributed to the conceptualization, funding acquisition, investigation and methodology. Heather Prior contributed to the conceptualization and methodology. Moneca Sinclaire contributed to the conceptualization and project administration. Annette Schultz, Lindsey Dahl, Thang Nguyen and Randy Fransoo contributed to writing the original draft, and all coauthors reviewed the article. All authors gave final approval of the version to be published and agreed to be accountable for all aspects of the work.

Funding: Funding was provided by the Canadian Institutes of Health Research (MOP-136904) through the Institute of Indigenous People's Health.

Data sharing: The data used in this study included linking information collected from a medical chart review to the Manitoba Population Research Data Repository housed at the Manitoba Centre for Health Policy (MCHP). Chart review was completed by trained study staff, and the data were deidentified at the Ministry of Health, Seniors and Active Living so that they could be brought into the repository at MCHP. The repository data are protected by legislation to ensure security, privacy and confidentiality. Access to the repository is granted only to accredited researchers to conduct studies, which must be approved by ethics and privacy review boards.

Acknowledgements: The authors acknowledge MCHP for use of data contained in the Manitoba Population Research Data Repository under Health Information Privacy Committee file no. 2014/2015-34. The results and conclusions are those of the authors, and no official endorsement by MCHP, Manitoba Health Seniors and Active Living or other data providers is intended or should be inferred. The authors acknowledge and thank the First Nations Health and Social Secretariat of Manitoba (FNHSSM) research team for their review and comments on this article, and acknowledge that FNHSSM Health Information Research Governance Committee has approved this project in development and final stages in 2015. The authors gratefully acknowledge Rady Faculty of Health Sciences Elder Mary Wilson, Grandmother of the Four Paths, for her insights concerning this manuscript and her involvement in the larger study.

Supplemental information: For reviewer comments and the original submission of this manuscript, please see www.cmajopen.ca/content/8/4/ E685/suppl/DC1. 